\title{
Compositional and drug-resistance profiling of pathogens in patients with severe acute pancreatitis: a retrospective study
}

Ning Fan ${ }^{1 \dagger}$, Yong Hu${ }^{2 \dagger}$, Hong Shen ${ }^{3 \dagger}$, Shengjie Liư ${ }^{4}$, Guang Zhao ${ }^{5}$, Lanju Sun ${ }^{4}$, Chunyan Li ${ }^{6}$, Xin Zhao ${ }^{7}$, Yanning $\mathrm{Li}^{1}$, Jianhua Wang ${ }^{1}$ and Yunfeng Cui ${ }^{4,8^{*}}$ (D)

\begin{abstract}
Background: Infection is one of the important causes of death in patients with severe acute pancreatitis (SAP), but the bacterial spectrum and antibiotic resistance are constantly changing. Making good use of antibiotics and controlling multi-drug-resistant (MDR) bacterial infections are of vital importance in improving the cure rate of SAP. We conducted a retrospective study in the hope of providing references for antibiotic selection and control of drug-resistant bacteria.
\end{abstract}

Methods: Retrospective analysis was performed on the data of patients hospitalized in our hospital due to acute pancreatitis (AP) in the past 5 years. General data were classified and statistically analyzed. Subsequently, the bacterial spectrum characteristics and the data related to drug-resistant bacterial infection of 569 AP patients were analyzed. Finally, unconditional logistic regression analysis was conducted to analyze the risk factors of MDR infection.

Results: A total of 398 patients were enrolled in this study and the hospitalization data and associated results were analyzed. A total of 461 strains of pathogenic bacteria were detected, including 223 (48.4\%) gram-negative bacterial strains, 190 (41.2\%) gram-positive bacterial strains and 48 (10.4\%) fungal strains. The detection rates of resistance in gram-negative and gram-positive bacterial strains were $48.0 \%$ (107/223) and 25.3\% (48/190), respectively. There were significant differences between the MDR group and the non-MDR group for the factors of precautionary antibiotic use, kinds of antibiotics used, receipt of carbapenem, tracheal intubation, hemofiltration and number of hospitalization days in the intensive care unit. Unconditional logistic regression revealed 2 risk factors for MDR bacterial infection.

Conclusions: Our results illustrate that gram-negative bacteria were the most common pathogens in SAP infection, and the proportion of gram-positive bacteria increased notably. The rate of antibiotic resistance was higher than previously reported. Unconditional logistic regression analysis showed that using more types of antibiotics and the number of hospitalization days in the ICU were the risk factors associated with MDR bacterial infection.

Keywords: Severe acute pancreatitis, Multi-drug resistant bacteria, Bacteria spectrum, Antibiotic resistance, Risk factors

\section{*Correspondence: nkyycyf@163.com}

${ }^{\dagger}$ Ning Fan, Yong Hu and Hong Shen contributed equally to this work

${ }^{8}$ Department of Surgery, Tianjin Nankai Hospital, Nankai Clinical School of Medicine, Tianjin Medical University, 122 Sanwei Road Nankai District, Tianjin, China

Full list of author information is available at the end of the article

\section{Introduction}

Acute pancreatitis (AP) is an inflammatory injury with pancreatic edema, hemorrhage and necrosis caused by the self-digestion of pancreatic tissue. Clinical features include acute upper abdominal pain and the elevation of amylase or lipase. AP is classified as mild acute 
pancreatitis (MAP), moderate to severe acute pancreatitis (MSAP) and severe acute pancreatitis (SAP). SAP is a critical condition with poor prognosis in the clinic. The mortality rate may be up to $30 \%$ [1] due to local and systemic complications, including systemic inflammatory response syndrome (SIRS), acute respiratory distress syndrome (ARDS) or multiple organ dysfunction syndrome (MODS) in the early stage [2-4]. Subsequently, infectious pancreatic necrosis (IPN) will appear in approximately 40 to $70 \%$ of patients in the second stage [5, 6], and the mortality rate can be as high as 32 to $50 \%$ [7-8] Currently, the treatment of IPN has evolved from open surgery to comprehensive treatment based on minimally invasive techniques, such as endoscopic treatments, percutaneous drainage and minimally invasive necrotic tissue removal [9-11].

Antibiotics are used for almost the entire treatment process [12]. This is because pancreatic and peripancreatic infectious necrosis is mainly caused by intestinal bacterial translocation [13, 14]. However, existing control methods cannot effectively prevent this process, a series of complex infections, such as MDR bacterial infections and fungal infections, often occur in the course of disease development. As such, it is necessary to actively seek prevention and treatment strategies; early use of antibacterial drugs to prevent pancreatic infection is a common method. Because some antibacterial drugs cannot effectively act on the pancreas in the case of systemic drug delivery, there is no effective antibacterial drug that can penetrate necrotic tissue without a blood supply, which increases the difficulty of antibiotic treatment [15]. However, imipenem, clindamycin, piperacillin, fluoroquinolone and metronidazole have sufficient tissue penetration and bactericidal properties for infectious pancreatic necrosis and have certain advantages in preventing and treating IPN [16]. There is still controversy about the prophylactic use of antibiotics to prevent infection $[17,18]$. How to identify pancreatic infections early, how to choose antibacterial drugs and how to time treatments are still major problems to be solved in the clinic.

The main purpose of this study includes two aspects. First, analyzing the characteristics of the bacterial spectrum and the changes in antibiotic resistance in AP patients is helpful to guide the preventive and empirical use of antibiotics. Second, the analysis of the risk factors for MDR bacterial infections can help doctors avoid particular treatments when controlling infections and delay or reduce MDR bacterial infections as much as possible.

\section{Methods}

\section{General information}

The data of MAP, MSAP and SAP patients hospitalized in our hospital were collected respectively, according to their diagnoses at the time of discharge. The time range of MAP and MSAP groups was from January 1, 2019 to December 31, 2019. The SAP group collected data over the past five years from January 1, 2015 to December 31, 2019. The patients in SAP group were divided into MDR group and Non-MDR group according to whether they had MDR infection. All patients must meet inclusion and exclusion criteria.

\section{Inclusion and exclusion criteria}

The inclusion criteria were as follows: (1) the patients met the AP diagnostic criteria proposed by the Atlanta consensus meeting [19], and (2) the results of the bacterial culture confirmed the pathogen diagnosis for infection. The exclusion criteria were as follows: (1) patients experiencing pregnancy-associated pancreatitis (2) the presence of a malignant tumor, (3) long-term use of immunosuppressive agents or patients with immune deficiency diseases, and (4) patients with incomplete hospitalization data.

\section{Data collection instructions}

Bacterial culture data and drug sensitivity test data were collected, including abdominal drainage fluid, sputum, blood, bile, deep venous catheter, and urine. The pathogens from the same patient and specimens were not counted repeatedly.

The date collection time points were as follows: at admission, 2 weeks after admission, 1 month after admission, and when the patient's clinical condition showed a major turning point. These changes include: (1) the body temperature was above $38{ }^{\circ} \mathrm{C}$ or below $36{ }^{\circ} \mathrm{C}$; (2) the patient experienced tachycardia, persistent hypotension (systolic blood pressure below $90 \mathrm{mmHg}$ ) or shortness of breath; (3) the patient experienced chills; (4) white blood cell counts increased or were extremely low (white blood cell count (WBC): 18,000 cells $/ \mathrm{mm}^{3}$ or WBC $<4000$ cell/ $\mathrm{mm}^{3}$ ); (5) platelet counts were $<150,000 \mathrm{cell} / \mathrm{mm}^{3}$, (6) the patient experienced an unexplained elevated CRP in the immunosuppressed state; (7) creatinine levels were $>2.0 \mathrm{mg} / \mathrm{dL}$; or (8) other suspected conditions worsened [20-22].

Risk factors were selected according to the factors that may cause MDR infection as reported in previous literature and clinically invasive procedures [23-26].

\section{Definitions}

MDR bacteria were defined by the following criteria [27]: (1) third-generation cephalosporin-resistant, (2) $\beta$-lactam-resistant Enterobacteriaceae (e.g., Escherichia coli, Klebsiella pneumonia, and Serratia marcescens), (3) MDR gram-negative rods defined as other gram-negative rods not susceptible to at least one agent in three or more 
antimicrobial categories (e.g., Acinetobacter baumannii, and Pseudomonas aeruginosa), (4) methicillin-resistant Staphylococcus aureus (MRSA), (5) methicillin-resistant, coagulase-negative staphylococci (MRCNS), and (6) vancomycin-resistant Enterococcus species (VRE).

\section{Strain treatment}

The specimens were cultured using a French BioMerieux BacT/ALERT 3D automatic blood training instrument and a $\mathrm{CO}_{2}$ incubator. A VITEK 2 compact automatic microbiological analyzer was used to identify the positive specimens for drug susceptibility tests. The susceptibility test was based on a breakpoint set by the American Association of Clinical Laboratory Standards (CLSI) in 2015 to determine drug resistance [28]. The quality control strains included Escherichia coli ATCC25922, Enterobacter cloacae ATCC700323, Staphylococcus aureus ATCC29213 and Streptococcus pneumoniae ATCC49619.

\section{Statistical analysis}

WHONET V.5.6 for Windows (WHO Collaborating Center, Boston) was used to collect the data and analyze the pathogens for drug resistance. SPSS V.22.0 for Windows (SPSS Inc., Chicago, IL) was used for statistical analysis, and enumeration data were checked by the chisquare test according to whether the measurement data were normally distributed. A t-test or rank sum test was performed. Fisher's exact test was used for the dichotomous contingency table, according to variable types. A univariate analysis was included in the unconditional logistic regression analysis model to calculate odds ratios (ORs) along with 95\% confidence intervals (CIs) to assess the strength of any association, and a 2 -sided $P<0.05$ was considered statistically significant.

\section{Results}

\section{Clinical data comparison}

A total of 569 AP patients were retrieved, 127 were excluded owing to the lack of bacterial culture, and 398 were eligible according to the exclusion criteria. There were 198 patients in MAP group, 29 in MSAP group and 171 in SAP group. A detailed study flow-diagram is shown in Fig. 1.

Statistical analysis showed that the total hospitalization days was significantly different among the MAP group, MSAP group and SAP group $(P=0.000)$. The death rate of the SAP group was significantly higher than that of the MAP group and MSAP group $(P=0.000)$. This is consistent with the severity of the disease (Table 1 ).

Of the 171 patients with SAP, 97 were male and 74 were female, with an average age of $52.4 \pm 16.3$ years old. The patients were divided into an MDR group (81 cases, $47.4 \%$ ) and a non-MDR group (90 cases, 52.6\%)
Table 1 Clinical data from the MAP, MSAP and SAP group

\begin{tabular}{llll}
\hline Items & MAP & MSAP & SAP \\
\hline Eligible number & 198 & 29 & 171 \\
Male & 111 & 18 & 97 \\
Femal & 87 & 11 & 74 \\
Age & $54.5 \pm 16.7$ & $53.8 \pm 15.4$ & $52.4 \pm 16.3$ \\
Etiology & & & \\
Chololithiasis & 129 & 15 & 83 \\
Hyperlipidaemia & 44 & 8 & 36 \\
Alcohol & 15 & 6 & 28 \\
Others & 10 & 0 & 24 \\
Total hospitalization days & $8.0 \pm 3.6$ & $24.0 \pm 14.4$ & $54 \pm 43.6$ \\
Death rate in hospital & 0 & 0 & 22 \\
\hline
\end{tabular}

Table 2 Clinical data from the MDR group and non-MDR group

\begin{tabular}{|c|c|c|c|}
\hline Characteristic & $\operatorname{MDR}(n=81)$ & non-MDR $(n=90)$ & $P$-value \\
\hline \multicolumn{4}{|l|}{ Gender } \\
\hline Male & $44(54.3 \%)$ & $53(58.9 \%)$ & 0.547 \\
\hline Female & $37(45.7 \%)$ & $37(41.1 \%)$ & \\
\hline Age & $52.4 \pm 16.9$ & $52.3 \pm 15.7$ & 0.972 \\
\hline \multicolumn{4}{|l|}{ Cause } \\
\hline Biliary & $38(46.9 \%)$ & $45(50.0 \%)$ & 0.678 \\
\hline Hyperlipidemia & $19(23.5 \%)$ & $17(18.9 \%)$ & 0.464 \\
\hline Alcohol & $13(16.1 \%)$ & $15(16.7 \%)$ & 0.913 \\
\hline Others $^{\mathrm{a}}$ & $11(13.6 \%)$ & $13(14.4 \%)$ & 0.683 \\
\hline BISAP score & $3.0 \pm 1.0$ & $2.6 \pm 1.1$ & 0.206 \\
\hline CTSI score & $6.6 \pm 1.4$ & $6 \pm 1.5$ & 0.104 \\
\hline APACHE II score & $15.6 \pm 8.6$ & $14.1 \pm 6.5$ & 0.204 \\
\hline MODS & 45 (55.6\%) & $38(42.2 \%)$ & 0.082 \\
\hline $\mathrm{SIRS}^{\mathrm{b}}$ & $81(100.0 \%)$ & $90(100.0 \%)$ & - \\
\hline Fungal infection & $28(34.6 \%)$ & $21(23.3 \%)$ & 0.105 \\
\hline Total hospitalization days & 45.3 & 36.1 & 0.062 \\
\hline Death rate in hospital & $15(18.5 \%)$ & $7(7.8 \%)$ & 0.036 \\
\hline
\end{tabular}

a SAP with unknown etiology

${ }^{\mathrm{b}}$ All patients had SIRS complications, and we were unable to perform independent statistical analyses

according to whether MDR bacterial infection was present. There were no significant differences in sex, age, cause of disease, severity of SAP, number of fungal infections and total hospitalization days between the two groups (Table 2).

\section{Distribution of pathogens}

A total of 654 strains of pathogenic bacteria were detected, including 348 strains of gram-negative bacteria, 


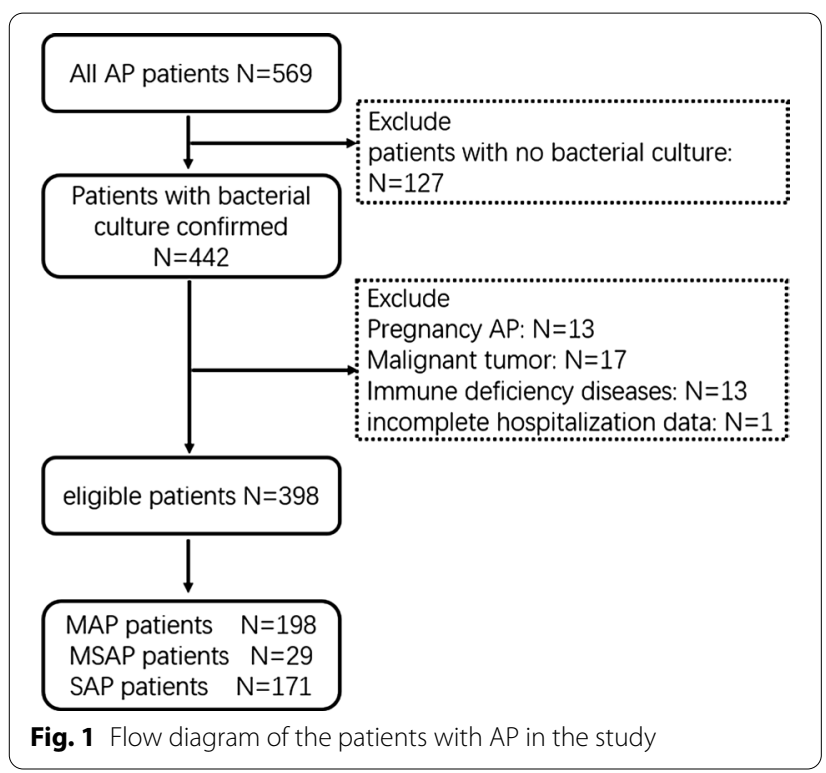

259 strains of gram-positive bacteria and 48 strains of fungi (Fig. 1).

In the SAP group, 461 pathogenic strains were detected, among which 223 strains were gram-negative and 190 strains were gram-positive. Escherichia coli was the dominant bacterium in gram-negative bacteria, while enterococcus faecium was the dominant bacteria group in gram-positive bacteria. All the fungi were detected in the SAP group. The source and strain quantities of pathogens are shown in Fig. 2.

\section{Main bacterial composition and MDR distribution in SAP group}

A total of 223 strains of gram-negative bacteria were detected in the SAP group, including 99 strains of MDR and 8 strains of extensively drug-resistant bacteria (XDR) Pseudomonas aeruginosa. For gram-positive bacteria, the detection rate of MDR bacteria was 25.3\% (48/190). There were 48 strains of fungus and no resistant strains (Figs. 3, 4).

\section{Antibiotic resistance analysis in SAP group Gram-negative}

The detection rates of extended-spectrum beta-lactamases (ESBL) in Escherichia coli and Klebsiella pneumoniae were $82.7 \%(43 / 52)$ and $65 \%(26 / 40)$, respectively. Escherichia coli and Klebsiella pneumoniae were sensitive to carbapenems, but the resistance rates of Pseudomonas aeruginosa and Acinetobacter baumannii to carbapenems were all over $50 \%$. The main bacterial strains were sensitive to piperacillin/tazobactam, except for Acinetobacter baumannii. The main gram-negative bacteria were sensitive to cefoperazone/sulbactam. A strain of tigecyclineresistant Klebsiella pneumoniae was detected (Fig. 5).

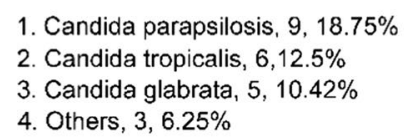

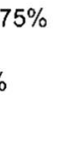

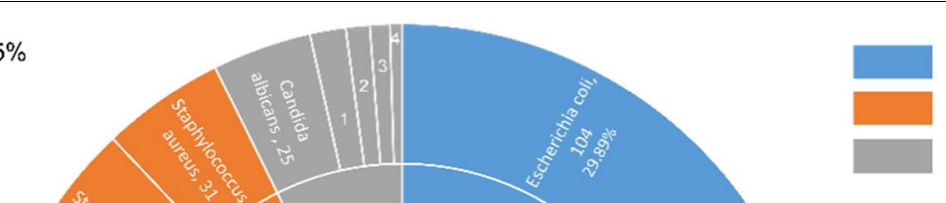

Gram-negative

Gram-positive

Fungi

Fig. 2 Strains composition diagram 


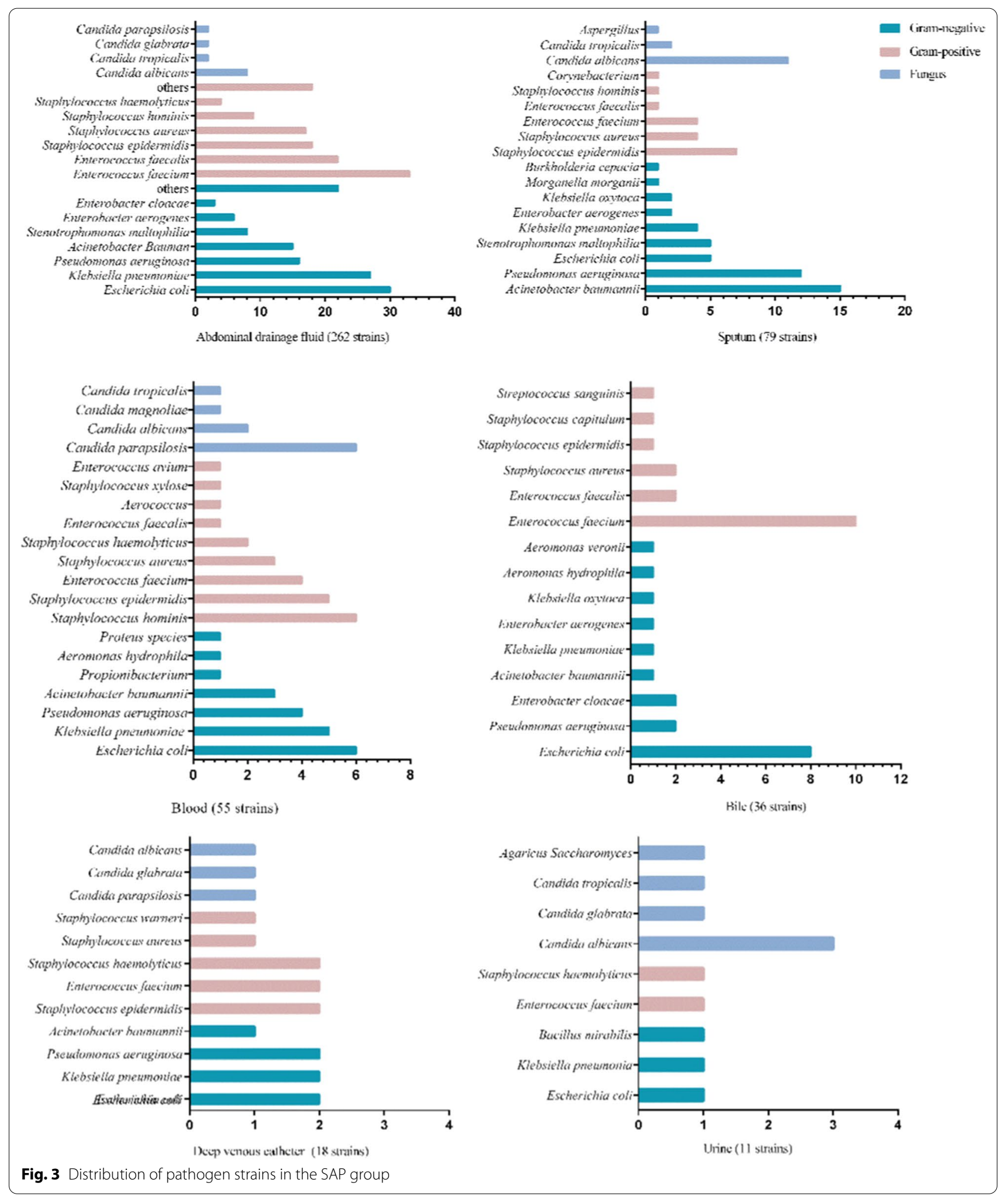

\section{Gram-positive}

The detection rate of MRSA was 10.5\% (20/190) and that of MRCNS was $2.1 \%$ (4/190). Among the enterococci, the resistance rates of Enterococcus faecium to benzyl penicillin and ampicillin were $85.2 \%$ and $83.3 \%$, respectively, while the resistance rates of Enterococcus faecalis were 


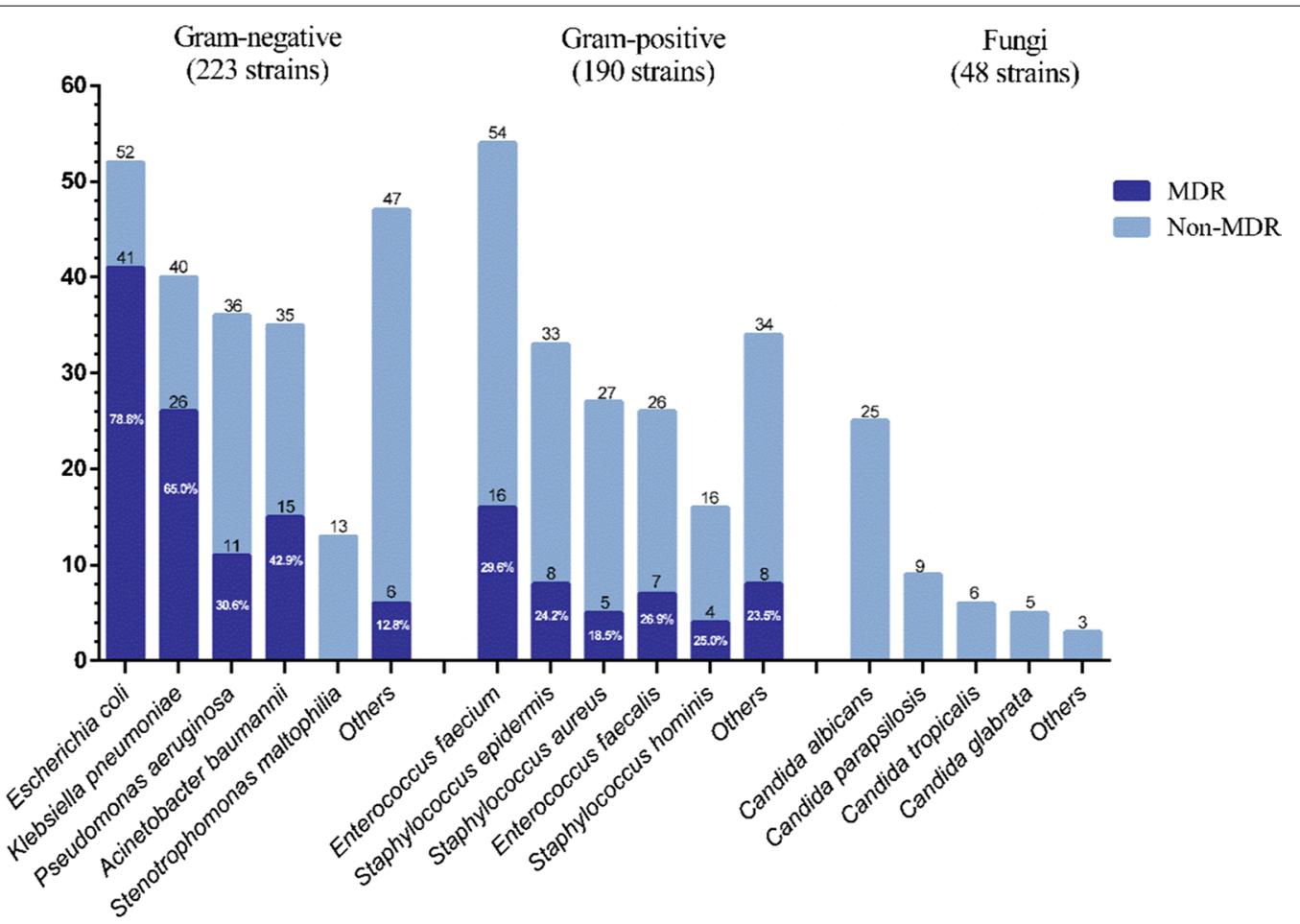

Fig. 4 Main bacterial composition and MDR distribution in SAP group

both $42.3 \%$. The resistance rates of Enterococcus faecium and Enterococcus faecalis to high concentration gentamicin combined with ampicillin were $64.8 \%$ and $57.7 \%$, respectively. There were no strains resistant to vancomycin, temozolomide or linezolid (Fig. 6).

\section{Comparison of MDR infection factors}

A total of 12 risk factors for MDR bacterial infection in the MDR and non-MDR groups were compared and included the following: precautionary antibiotic use, kinds of antibiotics used, use of carbapenem antibiotics, use of aminoglycoside antibiotics, average number of days of antibiotic use, endoscopic operation, intraperitoneal catheterization, venipuncture, preservation of the catheter, tracheal intubation, hemofiltration and number of hospitalization days in the ICU. Univariate analysis revealed 6 statistically significant infection factors, namely, precautionary antibiotic use $(P=0.030)$, kinds of antibiotic used $(P=0.005)$, use of carbapenem antibiotics $(P=0.009)$, tracheal intubation $(P=0.029)$, hemofiltration $(P=0.047)$ and number of hospitalization days in the ICU $(P=0.018)$ (Table 3).

\section{Risk factors}

MDR bacterial infection was the dependent variable, and the independent variables were precautionary antibiotic use, kinds of antibiotics used, receipt of carbapenem, receipt of aminoglycosides, endoscopic operation, tracheal intubation, hemofiltration and number of hospitalization days in the ICU. The independent variables were assigned from $\mathrm{X}_{1}$ to $\mathrm{X}_{8}$. Classification covariates were set to dummy variables, and 2 dummy variables were generated by $\mathrm{X} 2\left(\mathrm{X}_{2(1)}\right.$ represented $3<\mathrm{n}<7, \mathrm{X}_{2(2)}$ represented $\mathrm{n} \geq 7$ ).

$\mathrm{X}_{2(1)}$ was a high-risk factor for MDR bacterial infection (OR 3.319; 95\% CI 1.486-7.414; $P=0.003$ ), and $\mathrm{X}_{8}$ was a moderate risk factor for MDR bacterial infection (OR 1.048; 95\% CI 1.002-1.095; $P=0.039$ ) (Table 4).

\section{Discussion}

Our study found that there was no significant difference in the severity of SAP between the MDR and non-MDR groups. The mortality rate in the MDR group was significantly higher than that in the non-MDR group, which indicated that MDR bacterial infection was an important cause of death in SAP patients. This is because as the disease progresses, compensatory anti-inflammatory response syndrome (CARS) and SIRS compound one other and gradually worsen, resulting in mixed antagonistic response syndrome (MARS) [29]. The advantage of a proinflammatory response over an anti-inflammatory response is gradually reversed, and the patient sustains low levels of inflammation with severe immunosuppression development eventually [30]. SAP changes from an 


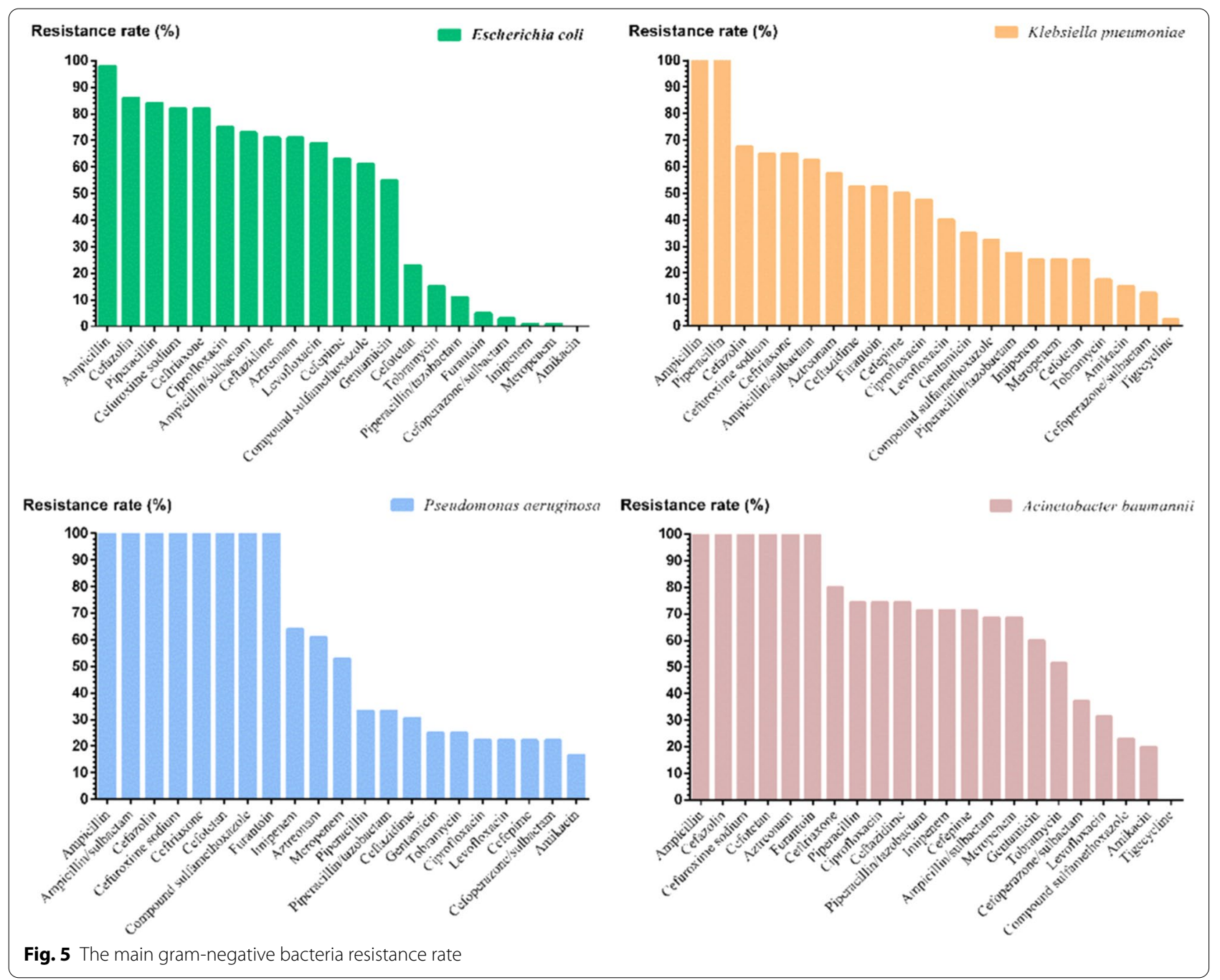

early aseptic chemical inflammation to a secondary multisite MDR bacterial infection; uncontrolled pancreatic and severe systemic infections cause sepsis, infectious bleeding, digestive tract spasms and other complications leading to death [31]. However, such findings must be interpreted cautiously because they are probably correlated with the fact that the peak of death occurred in the first and second stage, which was more frequent among patients who were more severely ill, while the MDR bacterial infection occurred later.

The total hospitalization days did not differ significantly between the two groups, which was related to the abandonment of treatment in some patients. Precautionary antibiotic use, kinds of antibiotics used, receipt of carbapenem, tracheal intubation, hemofiltration and number of hospitalization days in the intensive care unit were significantly higher in the MDR group. This indicates that the above interventions were important causes of MDR bacterial infections. Endoscopic surgery was a safe treatment measure for patients [32]. Unconditional logistic regression showed that ICU hospitalization was a risk factor for MDR bacterial infection [33]. When 4 to 6 different kinds of antibiotics used in patients, the risk of MDR bacterial infection was approximately 3 times that of patients given 1 to 3 antibiotics; therefore, we can draw the conclusion that using a variety of antibiotics increases the risk of MDR bacterial infection [34].

SAP infection was caused by pathogens that passed through the blood and bile duct systems or retrograded through the duodenum and ascended into the main pancreatic duct. At the same time, intestinal pathogens crossed the intestinal barrier and then translocated into the lymphatic system and the parenteral system to cause infection [35]. Although gram-negative bacteria were still dominant, the proportion of gram-positive bacteria increased notably compared with $27.9 \%$ and $23.9 \%$ reported by $\mathrm{Ma}$ [4] and $\mathrm{Su}$ [36]. One of the reasons is that drainage or postoperative infections occur after the 


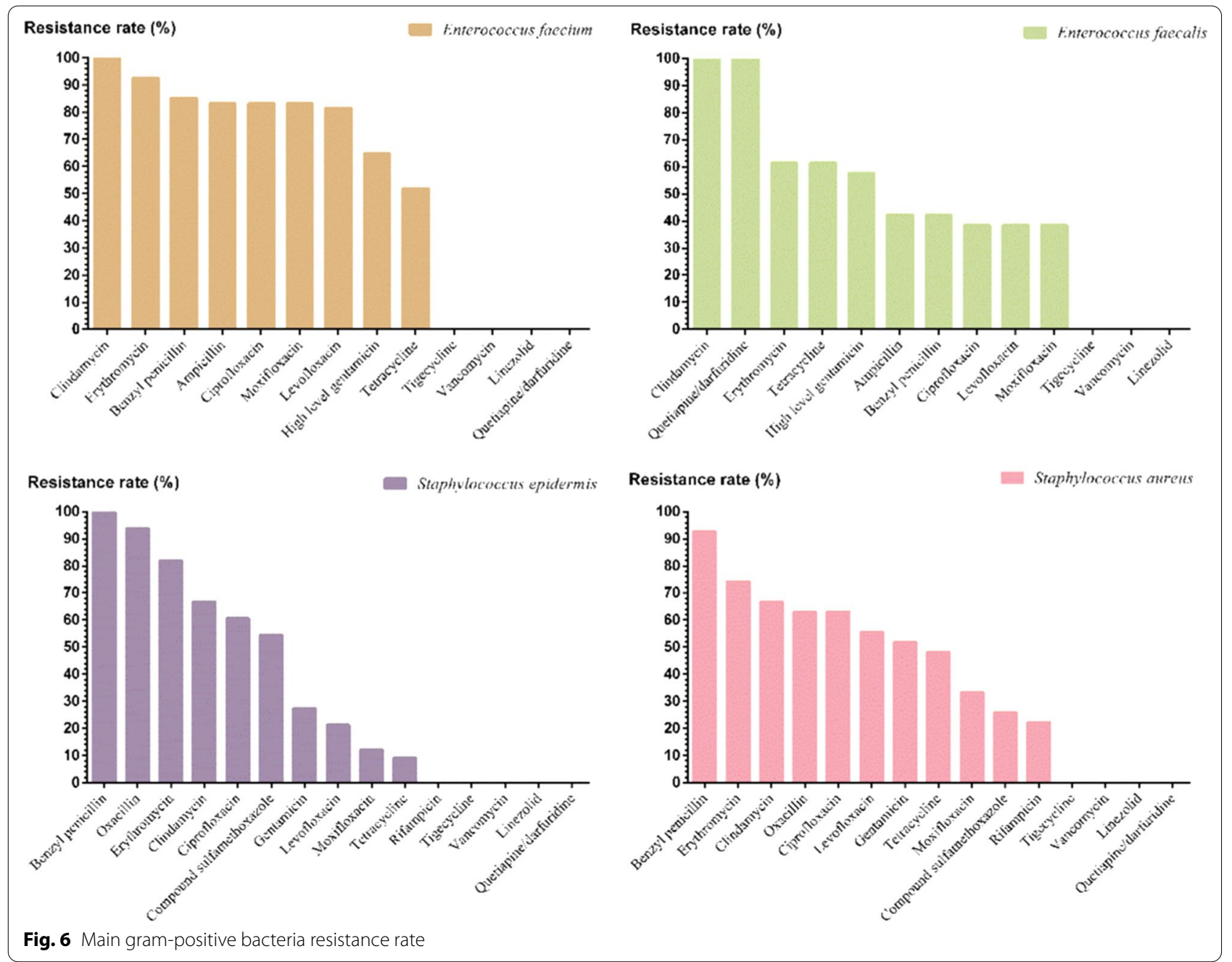

appearance of pancreatic or anastomotic fistula, leading to the emergence of multiple infection foci. However, the reason for the increase in the number of enterococci in SAP patients remains unclear and may be related to the prophylactic use of antibiotics [37]. Fernanda S. Soares [38] et al. found that prophylactic use of meropenem in SAP-affected mice induced Enterococcus colonization of the small intestine and gradually became predominant in the gut, which led to an increase in the number of gram-positive bacteria. A multihospital prospective clinical study showed that the intestinal population of Enterococcus was higher and more positively correlated with the serum levels of IL-6 in SAP patients than in MAP patients, suggesting that the increase in enterococci contributes to the severity of this disease [39].

The resistance rates of Escherichia coli and Klebsiella pneumoniae to quinolones were higher than those of nonfermentative bacteria, but the resistance rates to aminoglycosides were the opposite. Resistance to third generation cephalosporins by Enterobacteriaceae, which represents the major mechanism of antimicrobial resistance among Escherichia coli isolates [40]. Of the nonfermentative bacteria, Pseudomonas aeruginosa and Acinetobacter baumannii gradually exhibited resistance to carbapenems through an active efflux system and decreased permeability of the outer membrane [41, 42]. The drug resistance rates were higher than those of Escherichia coli and Klebsiella pneumoniae; therefore, it was necessary to combine treatment with $\beta$-lactamase inhibitors in the clinic [43]. The resistance rates of Escherichia coli and Klebsiella pneumoniae to cephalosporins were high, while the rates of Acinetobacter baumannii to ceftazidime and cefepime were higher than those of Pseudomonas aeruginosa. The rates of the main gram-negative bacteria to aztreonam were also higher, but Klebsiella pneumoniae and Acinetobacter baumannii were more sensitive to the compound sulfamethoxazole.

The detection rate of resistant Enterococcus faecium was higher than that of Enterococcus faecalis, and the resistance rates of these two bacteria to penicillin were 
Table 3 comparison of infection factors between the MDR group and non-MDR group

\begin{tabular}{|c|c|c|c|}
\hline Infection factors & $\operatorname{MDR}(n=81)$ & non-MDR $(n=90)$ & $P$-value \\
\hline Precautionary antibiotics & $44(54.3 \%)$ & $34(37.8 \%)$ & 0.030 \\
\hline Kinds of antibiotics & 3 & 2 & 0.005 \\
\hline Carbapenems & $58(71.6 \%)$ & $47(52.2 \%)$ & 0.009 \\
\hline Aminoglycosides & $8(9.9 \%)$ & $7(7.8 \%)$ & 0.628 \\
\hline Antibiotic days ${ }^{\mathrm{a}}$ & 34.1 & 27.0 & - \\
\hline Endoscopic operation ${ }^{\mathrm{b}}$ & $10(12.3 \%)$ & $10(11.1 \%)$ & 0.802 \\
\hline $\begin{array}{l}\text { Intraperitoneal } \\
\text { catheterization }^{c \S}\end{array}$ & $81(100.0 \%)$ & $90(100.0 \%)$ & - \\
\hline Venipuncture $^{d}$ & $81(100.0 \%)$ & $90(100.0 \%)$ & - \\
\hline Catheter preservation $^{\mathrm{d}}$ & $81(100.0 \%)$ & $90(100.0 \%)$ & - \\
\hline Tracheal intubation & $26(32.1 \%)$ & $16(17.8 \%)$ & 0.029 \\
\hline Hemofiltration & $9(11.1 \%)$ & $3(3.3 \%)$ & 0.047 \\
\hline $\begin{array}{l}\text { Hospitalization days in } \\
\text { the ICU }\end{array}$ & 13 & 4 & 0.018 \\
\hline
\end{tabular}

a Because of the social and human factors, the credibility of the data was low, so it was excluded.

Including ERCP, ENBD, endoscopic ultrasonography-guided puncture drainage, etc.

c Intraperitoneal catheterization included intraoperative abdominal catheterization and B ultrasound/CT guided abdominal puncture drainage

d All patients were included and were unable to perform independent statistical analyses

quite different; additionally, the resistance rates to high concentration gentamicin were all over $50 \%$, which was consistent with previous reports [44]. Therefore, the antibacterial effect was poorer for those pathogens when using aminoglycoside-penicillin or benzylpenicillin for synergistic effects and screening should be performed for clinical use. The detection rate of resistance in Staphylococcus epidermidis was higher than that in Staphylococcus aureus; however, the resistance rates of Staphylococcus aureus to quinolones and gentamicin were higher than those of Staphylococcus epidermidis. This is due to the formation of staphylococcus biofilms as an immune evasion and drug resistance mechanism [45]. Staphylococcus epidermidis was more sensitive to tetracycline, which was similar to the resistance of Staphylococcus aureus to compound sulfamethoxazole.
The prophylactic use of antibiotics for the prevention of secondary pancreatic infection remains controversial $[1,46]$, and the relevant guidelines are not recommended for patients with SAP and aseptic necrosis [47]. Although prophylactic use of carbapenem antibiotics may lead to bacterial translocation, according to the characteristics of the spectrum, drug sensitivity and antibiotic characteristics, the most appropriate method of empirical antibiotic treatment is meropenem. A short-term, full dose regimen of broad-spectrum antibacterials, especially carbapenems, in the early stage of SAP can eliminate sensitive pathogens quickly, reduce the dual-infection, and reduce the production of drug-resistant strains caused by bacterial flora disturbance. Subsequent use of antimicrobial agents should be based on the results of drug susceptibility testing of pathogens to ensure an effective antibacterial effect, shorten the course of treatment, reduce the production of drug-resistant strains and reduce the probability of fungal infection [48]. In our study, 53\% of patients with MDR bacterial infection had received prophylactic antibiotic treatment, and $38 \%$ of patients had not received preventive antibiotic treatment. There was no statistical difference between the use of prophylactic antibiotics and MDR bacterial infection.

Our study reports for the first time that more kinds of antibiotics and ICU hospitalization are associated with the development of MDR bacterial infections. This can help clinicians make a better choice to treat AP patients. However, our research also has some limitations. First, this is a single-center retrospective study with a small sample size and further research with larger sample sizes is needed. Moreover, there may be some deviation in the type and quantity of pathogenic bacteria because of the complexity of clinical treatment. Finally, our study cannot completely rule out the key factors for MDR bacterial infections.

\section{Conclusions}

The bacterial spectrum and drug resistance characteristics of SAP patients provide a certain reference for the empirical use of antibiotics and the regulation of intestinal microecological treatments. Our study found that gramnegative bacteria were the most common pathogens in

Table 4 Unconditioned logistic regression analysis of risk factors for MDR infection

\begin{tabular}{llllllll}
\hline Risk factors & B & S.E & Wald & df & P-value & OR & 95\% Cl \\
\hline$X_{2}$ & & & 9.464 & 2 & 0.009 & & \\
$X_{2(1)}$ & 1.200 & 0.410 & 8.557 & 1 & 0.003 & 3.319 & $1.486-7.414$ \\
$X_{2(2)}$ & -0.586 & 0.990 & 0.350 & 1 & 0.554 & 0.557 & $0.080-3.874$ \\
$X_{8}$ & 0.047 & 0.023 & 4.251 & 1 & 0.039 & 1.048 & $1.002-1.095$ \\
\hline
\end{tabular}

B, partial regression coefficient; $S$.E, standard error; $O R$, odds ratio; $C l$, confidence Interval. $X_{2}$, kinds of antibiotics; $X_{2(1)}$ represented $3<n<7, X_{2(2)}$ represented $n \geq 7 ; X_{8}$, hospitalization days in ICU 
SAP infection, and the proportion of gram-positive bacteria increased notably. Besides, more kinds of antibiotics and ICU hospitalization are risk factors for MDR bacterial infections.

\begin{abstract}
Abbreviations
SAP: Severe acute pancreatitis; IPN: Infectious pancreatic necrosis; MDR: Multidrug resistant; SIRS: Systemic inflammatory response syndrome; ARDS: Acute respiratory distress syndrome; MODS: Multiple organ dysfunction syndrome; MRSA: Methicillin-resistant Staphylococcus aureus; VRE: Vancomycin-resistant Enterococcus species; MRCNS: Methicillin-resistant coagulasenegative staphylococci; ORs: Odds ratios; Cls: Confidence intervals; ICU: Intensive care units; XDR: Extensively drug resistant; ESBL: Extended Spectrum Beta-Lactamases; CARS: Compensatory anti-inflammatory response syndrome; MARS: Mixed antagonistic response syndrome.
\end{abstract}

\section{Acknowledgements}

We thank the Association of Pancreatic Disease Specialized Committee of Tianjin Integrated Chinese and Western Medicine for their collaboration and assistance during the study. We thank all surgical colleagues from the Department of Surgery in Tianjin Nankai Hospital who have collaborated in this study.

\section{Authors' contributions}

YFC and YH conceived and designed the study. NF, YH, GZ, SL and LS performed the experiments. $C L, X Z, Y L$ and JW wrote the paper. YH and HS reviewed and edited. All authors read and approved the final manusript.

\section{Funding}

This study was funded by key project of Science and Technology of Tianjin Municipal Committee for health and family planning and Foundation of Tianjin Clinical Medical Research Center of Acute Abdomen with integrated Chinese and Western medicine.

\section{Availability of data and materials}

The datasets analysed during the current study are available from the corresponding author on reasonable request.

\section{Ethics approval and consent to participate}

This is a retrospective study and has been reviewed by the Medical Ethics Committee of Tianjin NanKai Hospital (NKYY_YX_IRB_2018_002_01). As the study was retrospective, no informed consent was required. All patients are anonymous and their information is not public.

\section{Consent for publication}

Not applicable.

\section{Competing interests}

The authors declare that they have no competing interests.

\begin{abstract}
Author details
${ }^{1}$ Department of Surgery, Beichen Chinese Medicine Hospital, Tianjin University of Traditional Chinese Medicine, Tianjin, China. ${ }^{2}$ Zhongnan Hospital of Wuhan University, No. 167, Donghu Road, Wuchang District, Wuhan 430000, China. ${ }^{3}$ Department of Surgery, Characteristic Medical Center of the Chinese People's Armed Police Force, Tianjin, China. ${ }^{4}$ Tianjin University of Traditional Chinese Medicine, Tianjin, China. ${ }^{5}$ Tianjin Nankai Hospital, Nankai Clinical School of Medicine, Tianjin Medical University, Tianjin, China. ${ }^{6}$ Department of Gastroenterology, Affiliated Hospital of Panzhihua University, Nanchong, China. ${ }^{7}$ Department of Breast Surgery,Affiliated Cancer Hospital of Zhengzhou University, Henan Cancer Hospital, Zhengzhou, China. ${ }^{8}$ Department of Surgery, Tianjin Nankai Hospital, Nankai Clinical School of Medicine, Tianjin Medical University, 122 Sanwei Road Nankai District, Tianjin, China.
\end{abstract}

Received: 17 July 2020 Accepted: 26 November 2020

Published online: 01 December 2020

\section{References}

1. Mourad MM, Evans R, Kalidindi V, Navaratnam R, Dvorkin L, Bramhall SR. Prophylactic antibiotics in acute pancreatitis: endless debate. Ann R Coll Surg Engl. 2017;99:107-12.

2. van Dijk SM, Hallensleben NDL, van Santvoort HC, Fockens P, van Goor H, Bruno MJ, et al. Acute pancreatitis: recent advances through randomised trials. Gut. 2017:66:2024-32.

3. Wolbrink DRJ, Kolwijck E, Ten Oever J, Horvath KD, Bouwense SAW, Schouten JA. Management of infected pancreatic necrosis in the intensive care unit: a narrative review. Clin Microbiol Inf. 2020;26:18-25.

4. Ma HX, He L, Cai SW, Xin XL, Shi HD, Zhou L, et al. Analysis of the spectrum and resistance of pathogen causing sepsis in patients with severe acute pancreatitis. Zhonghua wai ke za zhi [Chinese journal of surgery]. 2017:55:378-83.

5. Mallédant $Y$, Malbrain ML, Reuter DA. What's new in the management of severe acute pancreatitis? Intensive Care Med. 2015;41:1957-60.

6. Tugal D, Lynch M, Hujer AM, Rudin S, Perez F, Bonomo RA. Multi-drugresistant Klebsiella pneumoniae pancreatitis: a new challenge in a serious surgical infection. Surg Inf. 2015;16:188-93.

7. Petrov MS, Shanbhag S, Chakraborty M, Phillips AR, Windsor JA. Organ failure and infection of pancreatic necrosis as determinants of mortality in patients with acute pancreatitis. Gastroenterology. 2010;139:813-20.

8. van Santvoort HC, Bakker OJ, Bollen TL, Besselink MG, Ahmed Ali U, Schrijver AM, et al. A conservative and minimally invasive approach to necrotizing pancreatitis improves outcome. Gastroenterology. 2011;141:1254-63.

9. IAP/APA evidence-based guidelines for the management of acute pancreatitis. Pancreatology 2013;13:e1-15.

10. Hu Y, Jiang X, Li C, Cui Y. Outcomes from different minimally invasive approaches for infected necrotizing pancreatitis. Medicine. 2019:98:e16111.

11. HuY, Li C, Zhao X, Cui Y. An endoscopic or minimally invasive surgical approach for infected necrotizing pancreatitis: a systematic review and meta-analysis. Revista espanola de enfermedades digestivas : organo oficial de la Sociedad Espanola de Patologia Digestiva. 2019;111:471-80

12. Mowbray NG, Ben-Ismaeil B, Hammoda M, Shingler G, Al-Sarireh B. The microbiology of infected pancreatic necrosis. Hepatob Pancr Dis Int. 2018;17:456-60.

13. Baron EJ, Miller JM, Weinstein MP, Richter SS, Gilligan PH, Thomson RB Jr, et al. A guide to utilization of the microbiology laboratory for diagnosis of infectious diseases: 2013 recommendations by the Infectious Diseases Society of America (IDSA) and the American Society for Microbiology (ASM) (a). Clin Inf Dis. 2013;57:e22-121.

14. Jiang X, Shi JY, Wang XY, Hu Y, Cui YF. The impacts of infectious complications on outcomes in acute pancreatitis: a retrospective study. Military Med Res. 2020;7:38.

15. Manes G, Rabitti PG, Menchise A, Riccio E, Balzano A, Uomo G. Prophylaxis with meropenem of septic complications in acute pancreatitis: a randomized, controlled trial versus imipenem. Pancreas. 2003;27:e79-83.

16. Trudel JL, Wittnich C, Brown RA. Antibiotics bioavailability in acute experimental pancreatitis. J Am Coll Surg. 1994;178:475-9.

17. Tian $H$, Chen L, Wu X, Li F, Ma Y, Cai Y, et al. Infectious complications in severe acute pancreatitis: pathogens, drug resistance, and status of nosocomial infection in a university-affiliated teaching hospital. Dig Dis Sci. 2020;65:2079-88.

18. Baron TH, DiMaio CJ, Wang AY, Morgan KA. American gastroenterological association clinical practice update: management of pancreatic necrosis. Gastroenterology. 2020;158(67-75):e1.

19. Banks PA, Bollen TL, Dervenis C, Gooszen HG, Johnson CD, Sarr MG, et al. Classification of acute pancreatitis-2012: revision of the Atlanta classification and definitions by international consensus. Gut. 2013;62:102-11.

20. Shapiro NI, Wolfe RE, Wright SB, Moore R, Bates DW. Who needs a blood culture? A prospectively derived and validated prediction rule. J Emerg Med. 2008:35:255-64.

21. Canzoneri CN, Akhavan BJ, Tosur Z, Andrade PEA, Aisenberg GM. Followup blood cultures in gram-negative bacteremia: Are they needed? Clin Inf Dis. 2017:65:1776-9.

22. Coburn B, Morris AM, Tomlinson G, Detsky AS. Does this adult patient with suspected bacteremia require blood cultures? JAMA. 2012;308:502-11. 
23. Vazirani J, Wurity S, Ali MH. Multidrug-resistant pseudomonas aeruginosa keratitis: risk factors, clinical characteristics, and outcomes. Ophthalmology. 2015;122:2110-4.

24. Venier AG, Leroyer C, Slekovec C, Talon D, Bertrand X, Parer S, et al. Risk factors for Pseudomonas aeruginosa acquisition in intensive care units: a prospective multicentre study. J Hosp Inf. 2014;88:103-8.

25. Werge M, Novovic S, Roug S, Knudsen JD, Feldager E, Gluud LL, et al. Evaluation of local instillation of antibiotics in infected walled-off pancreatic necrosis. Pancreatology. 2018;18:642-6.

26. Sonmezer MC, Ertem G, Erdinc FS, Kaya Kilic E, Tulek N. Evaluation of Risk Factors for Antibiotic Resistance in Patients with Nosocomial Infections Caused by Pseudomonas aeruginosa. 2016;2016:1321487.

27. Lee HS, Lee SK, Park DH, Lee SS, Seo DW, Kim MH, et al. Emergence of multidrug resistant infection in patients with severe acute pancreatitis. Pancreatology [et al] 2014;14:450-453.

28. Bobenchik AM, Deak E, Hindler JA, Charlton CL, Humphries RM. Performance of Vitek 2 for antimicrobial susceptibility testing of Enterobacteriaceae with Vitek 2 (2009 FDA) and 2014 CLSI breakpoints. J Clin Microbiol. 2015;53:816-23.

29. Iskander KN, Osuchowski MF, Stearns-Kurosawa DJ, Kurosawa S, Stepien D, Valentine C, et al. Sepsis: multiple abnormalities, heterogeneous responses, and evolving understanding. Physiol Rev. 2013;93:1247-88.

30. Novotny AR, Reim D, Assfalg V, Altmayr F, Friess HM, Emmanuel K, et al. Mixed antagonist response and sepsis severity-dependent dysbalance of pro- and anti-inflammatory responses at the onset of postoperative sepsis. Immunobiology. 2012;217:616-21.

31. Yong FJ, Mao XY, Deng LH, Zhang MM, Xia Q. Continuous regional arterial infusion for the treatment of severe acute pancreatitis: a meta-analysis. Hepatob Pancr Dis Int. 2015;14:10-7.

32. da Costa DW, Boerma D, van Santvoort HC, Horvath KD, Werner J, Carter $C R$, et al. Staged multidisciplinary step-up management for necrotizing pancreatitis. Br J Surg. 2014;101:e65-79.

33. Peng Y, Bi J, Shi J, Li Y, Ye X, Chen X, et al. Multidrug-resistant Pseudomonas aeruginosa infections pose growing threat to health care-associated infection control in the hospitals of Southern China: a case-control surveillance study. Am J Infect Control. 2014;42:1308-11.

34. Huang X, Li G, Yi L, Li M. [The epidemiology of multidrug-resistant bacteria colonization and analysis of its risk factors in intensive care unit]. Wang J Zhonghua wei zhong bing ji jiu yi xue. 2015;27:667-71.

35. Fishman JE, Levy G, Alli V, Zheng X, Mole DJ, Deitch EA. The intestinal mucus layer is a critical component of the gut barrier that is damaged during acute pancreatitis. Shock (Augusta, Ga). 2014;42:264-70.

36. Su MS, Lin MH, Zhao QH, Liu ZW, He L, Jia N. Clinical study of distribution and drug resistance of pathogens in patients with severe acute pancreatitis. Chin Med J. 2012;125:1772-6.
37. Howard TJ, Temple MB. Prophylactic antibiotics alter the bacteriology of infected necrosis in severe acute pancreatitis. J Am Coll Surg. 2002;195:759-67.

38. Soares FS, Amaral FC, Silva NLC, Valente MR, Santos LKR, Yamashiro LH, et al. Antibiotic-induced pathobiont dissemination accelerates mortality in severe experimental pancreatitis. Front Immunol. 2017;8:1890.

39. Tan C, Ling Z, Huang Y, Cao Y, Liu Q, Cai T, et al. Dysbiosis of intestinal microbiota associated with inflammation involved in the progression of acute pancreatitis. Pancreas. 2015;44:868-75.

40. Trecarichi EM, Giuliano G, Cattaneo C, Ballanti S, Criscuolo M, Candoni A, et al. Bloodstream infections caused by Escherichia coli in onco-haematological patients: Risk factors and mortality in an Italian prospective survey. 2019;14:e0224465.

41. Lai CC, Chen CC, Lu YC, Chuang YC, Tang HJ. In vitro activity of cefoperazone and cefoperazone-sulbactam against carbapenem-resistant Acinetobacter baumannii and Pseudomonas aeruginosa. Inf Drug Resist. 2019;12:25-9.

42. Potron A, Poirel L, Nordmann P. Emerging broad-spectrum resistance in Pseudomonas aeruginosa and Acinetobacter baumannii: mechanisms and epidemiology. Int J Antimicrob Agents. 2015;45:568-85.

43. Ambrose PG, Lomovskaya O, Griffith DC, Dudley MN, VanScoy B. $\beta$-Lactamase inhibitors: what you really need to know. Curr Opin Pharmacol. 2017;36:86-93.

44. Wang JT, Chang SC, Wang HY, Chen PC, Shiau YR, Lauderdale TL. High rates of multidrug resistance in Enterococcus faecalis and $\mathrm{E}$. faecium isolated from inpatients and outpatients in Taiwan. Diagn Microbiol Inf Dis. 2013;75:406-11.

45. Otto M. Staphylococcus epidermidis pathogenesis. Methods Mol Biol (Clifton, NJ). 2014;1106:17-31.

46. Ukai T, Shikata S, Inoue M, Noguchi Y, Igarashi H, Isaji S, et al. Early prophylactic antibiotics administration for acute necrotizing pancreatitis: a meta-analysis of randomized controlled trials. J Hepato-Biliary Pancr Sci. 2015;22:316-21.

47. Tenner S, Baillie J, DeWitt J, Vege SS. American College of Gastroenterology guideline: management of acute pancreatitis. Am J Gastroenterol. 2013;108(1400-15):16.

48. Schwender BJ, Gordon SR, Gardner TB. Risk factors for the development of intra-abdominal fungal infections in acute pancreatitis. Pancreas. 2015;44:805-7.

\section{Publisher's Note}

Springer Nature remains neutral with regard to jurisdictional claims in published maps and institutional affiliations.
Ready to submit your research? Choose BMC and benefit from:

- fast, convenient online submission

- thorough peer review by experienced researchers in your field

- rapid publication on acceptance

- support for research data, including large and complex data types

- gold Open Access which fosters wider collaboration and increased citations

- maximum visibility for your research: over $100 \mathrm{M}$ website views per year

At BMC, research is always in progress.

Learn more biomedcentral.com/submissions 